\title{
Prevalence of cardiovascular risk factors in elderly from an agricultural area of morocco
}

\begin{abstract}
Background: Although a number of risk factors for cardiovascular morbidity and mortality have been identified in young and middle-aged adults, their prevalence and importance are less known in the elderly. In Morocco, elderly people have a risk profile different from that of younger subjects, but representative data on risk factors for cardiovascular disease in the elderly are difficult to find in the literature.
\end{abstract}

Objective: To investigate the prevalence of Cardiovascular risk factors among Moroccan elderly Individuals in the city of El Jadida in Morocco.

Methods: Data were collected from a randomized sample of 537 elderly individuals aged $\geq 60$ years, surveyed at household level Socioeconomic and demographic data, as well as data on lifestyle, weight, height, waist circumference, blood pressure and medications used were collected. The prevalence of cardiovascular risk factors: hypertension, diabetes mellitus, total obesity, central obesity, dyslipidemias, smoking and alcohol consumption were determined.

Results: The prevalence of the Cardiovascular risk factors were: $66,1 \%$ for hypertension; $24.2 \%$ for general obesity; $25.3 \%$ for central obesity; $14.9 \%$ for diabetes mellitus; $6.7 \%$ for smoking and $10 \%$ for alcohol consumption. The population studied showed elevated total cholesterol, total triglycerides and low HDL-C levels among $4 \%, 12.3 \%$ and $16.2 \%$ respectively. Obesity and central obesity were more prevalent in women while that of hypertension was higher in men. The simultaneity of two or more cardiovascular risk factors occurred in $54.3 \%$ of the elderly and was more frequent among women while $11.4 \%$ of the elderly did not have any cardiovascular risk factors

Conclusion: The cardiovascular risk factors occur simultaneously in more than half of the elderly individuals, and the most prevalent ones were: hypertension, central and total obesity. It is necessary to foster the strategies of health promotion and prevention of cardiovascular injury in elderly individuals in the city of El Jadida.

Keywords: cardiovascular diseases, risk factors, elderly
Volume 6 Issue 4 - 2017

\author{
Ahaji Azzelarab,' Mziwira Mohamed,',2 \\ Eladlouni Chakib,' Chafik Abdelaziz,' \\ Belahsen Rekia' \\ 'Chouaib Doukkali University School of Sciences, Morocco \\ ${ }^{2}$ Hassan II University, Morocco
}

\begin{abstract}
Correspondence: Rekia Belahsen, Laboratory of Biotechnology, Biochemistry \& Nutrition, Training and Research Unit on Nutrition \& Food Sciences, Chouaib Doukkali University, School of Sciences, El Jadida, 24000 Morocco, Tel 212 52334 2325/2I2 664 971616, Fax 2125233421 87/4449. Email rbelahsen@yahoo.com
\end{abstract}

Received: March 02, 2017 | Published: March 23, 2017

\section{Introduction}

Cardiovascular diseases are currently the leading cause of death Studies conducted in Morocco shows a higher prevalence of these factors in urban than in rural areas. ${ }^{1,2}$ However, as the majority of these studies have not targeted the elderly and no typical data are available for this population. The impact of these diseases is on the increase because of the population aging, socio-economic changes and growth of urbanization. In Morocco, the age pyramid is changing. Its broad base in the 1960s is currently shrinking for the under-15s in favor of the 16 to 59 -years-old and the over-60s. Consequently, the number of elderly people rose from less than one million in 1960 to 2.4 million in 2004 and 3.2 million in 2014 (9.4\% of the total population), and this number is projected to grow to achieve 5.8million in 2030, (15.4 $\%$ of the total population), an average annual rate of $3.5 \%$, which will represent the double of the current level. ${ }^{3,4}$ As a result, the onset of population aging will increasingly affect the health care system due to the increase in medical problems specific to the elderly, namely chronic and degenerative diseases.

The total population of El jadida province increased from 1793458 to 19984039 between 1994 and 2004 with a growth rate of $1.3 \%$ (lower than in the whole country $(1.4 \%)), 2.2 \%$ of the population lives in urban areas and $1 \%$ in rural areas, people aged 60 and over represent $8.3 \%$ of which $4.4 \%$ are women. ${ }^{5}$ The present paper aimed to study the relationships between the prevalence of cardiovascular risk factors; some socio-economic and demographic variables; the clinical characteristics and the concurrency of cardiovascular risk factors among the elderly in the city of El Jadida.

\section{Materials and methods}

The study population consisted of 537 elderly individuals aged $\geq 60$ years, of both sexes selected from a study undertaken at household level on a total sample of 1019 in El Jadida province. The study procedures were carried out by trained in standardized interviews and anthropometric measures, during a pilot study. The data were collected from April 2015 to December 2015, by pairs of professionals, consisting of one anthropometrist and one interviewer. The recruitment was made according to age. Individuals with physical or mental disabilities that could jeopardize the procedures or those who could not understand the written formal consent, and those residing in the city for less than 3years were excluded from the study.

Height $( \pm 0.5 \mathrm{~cm})$ and weight $( \pm 0.5 \mathrm{~kg})$ were measured and body mass index (BMI) was calculated as body weight $(\mathrm{kg})$ divided by the square of height $(\mathrm{m})$ and the WHO cutoff points for overweight $(\mathrm{BMI}>25)$ and obesity $(\mathrm{BMI})>30)$ were used as measures of general obesity. ${ }^{6}$ Waist circumference (WC) at midway between the lowest 
rib and the iliac crest and hip circumference at the greater trochanter were measured to the nearest millimeter using a flexible tape. WC was measured to assess central obesity, specifically as an indicator of intra-abdominal or visceral fat deposition. A WC $\geq 88 \mathrm{~cm}$ for women and $\geq 102 \mathrm{~cm}$ for men was considered as cardiovascular risk factor. A mean of two separate measurements was used in the analysis. ${ }^{7,8}$

Blood pressure (BP) was measured in a sitting position using a mercury sphygmomanometer after at least 10 min rest. High BP was defined according to the Adult Treatment Panel III criteria: systolic blood pressure $\geq 130 \mathrm{mmHg}$ and/or diastolic $\geq 85 \mathrm{mmHg}$ or on treatment for hypertension. ${ }^{9}$ Furthermore, blood samples were collected after $12 \mathrm{~h}$ overnight fasting and the plasma was separated by centrifugation and stored at $-900 \mathrm{C}$ until determinations.

Total cholesterol (TC), triglycerides (TG) and high density lipoprotein Cholesterol (HDL) are determined by enzymatic methods. The level of blood glucose was determined in fasting phase by enzymatic method. All biological analyses are determined using a biochemistry automated analyzer (CS-T240) and concentration of low-density lipoprotein cholesterol (LDL-C) was calculated using the Friedewald formula. ${ }^{10}$ Lipid and lipoprotein values were expressed asmmol/l.

Hypercholesterolemia was defined as mild for cholesterol values in the range $5.2-6.2 \mathrm{mmol} / 1$ and moderate to severe for cholesterol value $6.2 \mathrm{mmol} / 1$. Hypo-HDL cholesterolemia was defined for values lower than $0.9 \mathrm{mmol} / 1$ and hypertrigyceridemia was defined for values higher than $1.725 \mathrm{mmol} / 1 .{ }^{11}$ Hyperglycemia was defined when fasting blood glucose was greater than 6.1 and less than $6.9 \mathrm{mmol} / 1$, and diabetes when fasting blood glucose was greater than $7 \mathrm{mmol} / 1{ }^{11}$

As there are no Moroccan norms for lipid and lipoprotein levels, the European standards were used. Tobaco use was considered present in individuals reporting smoking until the day of the interview. Alcohol consumption was assessed based on questions regarding the consumption of alcoholic beverages (yes/no), the type of alcoholic beverage, the frequency and the amount (doses, bottles or glasses) of alcohol consumed during the previous week and then, the number of grams of ethanol per day was determined. All statistical analyzes were performed using the Statistical Package for the Social Sciences (SPSS Inc., Chicago, IL, USA). The categorical variables are given as percentages. Associations among different groups and variables were analyzed with the Chi-square test. Tukey's test was used for comparisons of the metabolic variables means. A P value less than 0.05 was considered statistically significant.

\section{Results and discussion}

A total of 537 elderly individuals were surveyed and the sample was characterized by a predominance of males $(74.0 \%)$, a mean age of $68.5 \pm 4$ years (60 to 83years) and a degree of illiteracy of $27 \%$. Table 1 shows that most of the assessed sample, around $95 \%(\mathrm{n}=512)$ was at the age range of 60 to 74 years. Regarding the socioeconomic profile, it was observed that $29.6 \%$ had completed up to the $12^{\text {th }}$ years of Elementary School but men presented a better degree of schooling $(p=0.000)$. The frequency of elderly individuals that were married or lived with a partner was higher among men $(94.8 \%)$. The prevalence of general obesity was $24.2 \%$ with a higher prevalence among women $(\mathrm{p}=0.000)$.

Table I Description of socioeconomic and demographic variables and nutritional status, according to sex, of the elderly individuals of the city of El jadida

\begin{tabular}{|c|c|c|c|c|c|c|c|}
\hline \multirow{2}{*}{ Variables } & \multicolumn{2}{|c|}{ Total $(n=537)$} & \multicolumn{2}{|c|}{ Male $(n=40 I)$} & \multicolumn{2}{|c|}{ Female $(n=136)$} & \multirow[t]{2}{*}{ PValue* } \\
\hline & $\mathbf{N}$ & $\%$ & $\mathbf{N}$ & $\%$ & $\mathbf{N}$ & $\%$ & \\
\hline Age range & & & & & & & 0 \\
\hline 60 to 64 & 109 & 20.3 & 25 & 6.2 & 84 & 61.8 & \\
\hline 65 to 69 & 180 & 33.5 & 143 & 35.7 & 37 & 27.2 & \\
\hline 70 to 74 & 223 & 41.5 & 211 & 52.6 & 12 & 8.8 & \\
\hline$\geq 75$ & 25 & 4.7 & 22 & 5.5 & 3 & 2.2 & \\
\hline Years of schooling & & & & & & & 0 \\
\hline Illiterate & 145 & 27 & 74 & 18.5 & 71 & 52.2 & \\
\hline Primary & 32 & 6 & 25 & 6.2 & 7 & 5.1 & \\
\hline Secondary & 127 & 23.6 & 119 & 29.7 & 8 & 5.9 & \\
\hline University & 233 & 43.4 & 183 & 45.6 & 50 & 36.8 & \\
\hline Area of residence & & & & & & & 0.535 \\
\hline Rural & 288 & 53.6 & 215 & 53.6 & 73 & 53.7 & \\
\hline Urban & 249 & 46.4 & 186 & 46.4 & 63 & 46.3 & \\
\hline Marital status & & & & & & 0.008 & \\
\hline Lives with partner & 499 & 92.9 & 380 & 94.8 & 119 & 87.5 & \\
\hline Lives without partner & 38 & 7.1 & 21 & 5.2 & 17 & 12.5 & \\
\hline Nutritional status (BMI: kg/m²) & & & & & & & 0.008 \\
\hline Underweight $(\mathrm{BMI}<18.5)$ & 0 & 0 & 0 & 0 & 0 & 0 & \\
\hline Normal Weight (BMI I8.5 to 24.99) & 142 & 26.4 & 115 & 28.7 & 27 & 19.9 & \\
\hline Overweight (BMI 25 to 29.99) & 265 & 49.3 & 222 & 55.4 & 43 & 31.6 & \\
\hline Obesity (BMI $\geq 30$ ) & 130 & 24.2 & 64 & 16 & 66 & 48.5 & 0 \\
\hline
\end{tabular}


The Table 2a shows that the mean blood pressure (systolic and diastolic) was higher in male while that of BMI was higher in female compared to their sex counterpart.

The cardiovascular risk factors, according to sex, are shown in Table $2 \mathrm{~b}$. The highest prevalence was observed for hypertension followed by central obesity, total obesity and Diabetes mellitus. Obesity and central obesity were more prevalent in women while that of hypertension was higher in men. Indeed, $75.6 \%$ of men and $38.2 \%$ of women were defined as hypertensive and Systolic hypertension (systolic blood pressure levels greater than $130 \mathrm{~mm} \mathrm{Hg}$ ) was observed in $63.7 \%$ of the studied population $(73.1 \%$ of men and $36 \%$ of women), while diastolic hypertension (diastolic blood pressure levels greater than $85 \mathrm{~mm} \mathrm{Hg}$ ) was observed in $19.9 \%$ (23,7\% of men and $8.8 \%$ of Women).

Table 2 Clinical characteristics and prevalence of cardiovascular risk factors according to sex in elderly individuals from El Jadida city

\begin{tabular}{|c|c|c|c|c|}
\hline Risk factors & Total $(n=537)$ & Male $(n=40 I)$ & Female $(n=136)$ & PValue* \\
\hline Systolic blood pressure $(\mathrm{mm} \mathrm{Hg})$ & $136.5 \pm 17.1$ & $140 \pm 16.7$ & $126.1 \pm 16.9$ & 0 \\
\hline Diastolic blood pressure $(\mathrm{mm} \mathrm{Hg})$ & $76.2 \pm 9.3$ & $77.6 \pm 8.9$ & $72.2 \pm 9.6$ & 0 \\
\hline Arterial hypertension & $355(66.1 \%)$ & $303(75.6 \%)$ & $52(38.2 \%)$ & 0 \\
\hline Body mass index $\left(\mathrm{kg} / \mathrm{m}^{2}\right)$ & $27.1 \pm 3.5$ & $26.3 \pm 2.8$ & $29.6 \pm 4.2$ & 0 \\
\hline Total obesity & $130(24.2 \%)$ & $64(16 \%)$ & $66(48.5 \%)$ & 0 \\
\hline Waist circumference(cm) & $92.8 \pm 11.1$ & $93.4 \pm 9.3$ & $91.1 \pm 15.1$ & 0 \\
\hline Central obesity & $136(25.3 \%)$ & $67(16.7 \%)$ & $69(50.7 \%)$ & 0.053 \\
\hline Blood glucose (mmol/L) & $I \pm 0.3$ & $I \pm 0.3$ & $0.9 \pm 0.3$ & 0.751 \\
\hline Diabetes mellitus & $80(14.9 \%)$ & $65(16.2 \%)$ & I5 (I I\%) & 0.09 \\
\hline Total serum cholesterol $(\mathrm{mmol} / \mathrm{L})$ & $1.7 \pm 0.3$ & $1.7 \pm 0.3$ & $1.7 \pm 0.3$ & 0.908 \\
\hline hypercholesterolemia & $22(4.1 \%)$ & $16(4 \%)$ & $6(4.4 \%)$ & 0.499 \\
\hline HDL-cholesterol ( $\mathrm{mmol} / \mathrm{L})$ & $0.4 \pm 0.1$ & $0.4 \pm 0.1$ & $0.4 \pm 0.1$ & 0.531 \\
\hline Hypo-HDL-C & $87(16.2 \%)$ & $56(14 \%)$ & 31 (22.8\%) & 0.013 \\
\hline Triglycerides $(\mathrm{mmol} / \mathrm{L})$ & $1.4 \pm 0.5$ & $1.4 \pm 0.5$ & $1.4 \pm 0.5$ & 0.436 \\
\hline Hyper Triglyceridemia & $66(12.3 \%)$ & $53(13.2 \%)$ & $13(9.6 \%)$ & 0.166 \\
\hline Smoking & $36(6.7 \%)$ & 34 (8.5 \%) & $2(1.5 \%)$ & 0.002 \\
\hline Alcohol consumption & $53(10 \%)$ & $52(13 \%)$ & I (0.7\%) & 0 \\
\hline
\end{tabular}

Smoking and alcohol consumption during the 30days before the survey were reported by $10 \%$ and $6.7 \%$ of the elderly individuals respectively with higher prevalent among men $(\mathrm{p}<0.005)$. $75.6 \%$ of men and $38.2 \%$ of women were defined as hypertensive. Systolic hypertension (systolic blood pressure levels greater than $130 \mathrm{~mm}$ $\mathrm{Hg}$ ) was observed in $63.7 \%$ of the studied population $(73.1 \%$ of men and $36 \%$ of women), while diastolic hypertension (diastolic blood pressure levels greater than $85 \mathrm{~mm} \mathrm{Hg})$ was observed in $19.9 \%(23,7 \%$ of men and $8.8 \%$ of Women).

On average the same total cholesterol levels were found in men and women and $4 \%$ of men and $4,4 \%$ of women had total serum cholesterol levels above the threshold of $6.2 \mathrm{mmol} / \mathrm{l}$. All of those who had abnormal total cholesterol levels at interview, reported that they were unaware about their condition. Similar results were observed regarding HDL - cholesterol (Table 2b). We also observed that $14 \%$ of men and $22,8 \%$ of women had very low HDL - cholesterol levels
$(<0.9 \mathrm{mmol} / 1)$. Triglycerides levels were higher in Men compared to women (Table 2). Approximately, 13, 2\% of men and 9,6\% of women had high triglycerides levels $(>1.725 \mathrm{mmol} / \mathrm{l})$. The Table 3 shows that total Obesity and central obesity were more prevalent in the 60 to 64years age category $(p<0.005)$. There was an increase in the frequency of Alcohol consumption with age which was higher among the elderly older than 75years $(<0.005)$. The same trend was observed for hypertension with an increase at the age range of $70 y e a r s$ and older $(<0.005)$. The simultaneity of risk factors is presented in the Table 4. The results show that $11.4 \%$ of the studied population did not present any risk factor. The prevalence of simultaneity of cardiovascular risk decreases with increasing number of risk factors in both sexes from $34 \%$ of the population with a single risk to $1.5 \%$ with 5 and more simultaneous risk factors. The total number of participants with three or more risk factors represents $26.7 \%$ of the total sample, with a higher frequency among women $(33.9 \%)$ than men $(24.2 \%)$. None of the elderly individuals presented all risk factors simultaneously. 
Table 3 Prevalence of cardiovascular risk factors according to age range in elderly individuals of El Jadida city

\begin{tabular}{|c|c|c|c|c|c|c|c|c|c|}
\hline \multirow{3}{*}{ Risk factors } & \multicolumn{9}{|c|}{ Age range (years) } \\
\hline & \multicolumn{2}{|c|}{60 to 64} & \multicolumn{2}{|c|}{65 to 69} & \multicolumn{2}{|c|}{70 to 74} & \multicolumn{2}{|c|}{75 or +} & \multirow{2}{*}{ PValue* } \\
\hline & $\%$ & $95 \% \mathrm{Cl}$ & $\%$ & $95 \% \mathrm{Cl}$ & $\%$ & $95 \% \mathrm{Cl}$ & $\%$ & $95 \% \mathrm{Cl}$ & \\
\hline Arterial hypertension & 51.4 & $50.45-52.29$ & 68.9 & $68.33-69.44$ & 70.9 & $70.4-71.3$ & 68 & $64-72$ & 0.004 \\
\hline Total obesity & 36.7 & $35.77-37.61$ & 17.2 & $16.66-17.77$ & 23.3 & $22.86-23.76$ & 28 & $24-32$ & 0.002 \\
\hline Central obesity & 37.6 & $36.69-38.53$ & 18.3 & |7.77-| 8.88 & 24.7 & $24.2 I-25.1 I$ & 28 & $24-32$ & 0.004 \\
\hline Diabetes mellitus & 14.7 & $13.76-15.59$ & 15 & $|4.44-| 5.55$ & 14.8 & $\mid 4.34-15.24$ & 16 & 20-Dec & 0.9 \\
\hline Hypercholesterolemia & 4.6 & $3.66-5.5$ & 2.8 & $2.77-3.88$ & 4.9 & $4.48-5.38$ & 4 & $0-12$ & 0.738 \\
\hline Hypo-HDL-C & 19.3 & $18.34-20.18$ & 18.9 & $18.33-19.44$ & 13 & $12.55-13.45$ & 12 & 16-Aug & 0.294 \\
\hline hypertriglyceridemia & 10.1 & $9.17-11$ & 15 & $14.44-15.55$ & 11.2 & $10.76-11.65$ & 12 & 16-Aug & 0.581 \\
\hline Smoking & 4.6 & $3.66-5.5$ & 5.6 & $5-6.11$ & 7.6 & $7.17-8.07$ & 16 & 20-Dec & 0.178 \\
\hline Alcohol consumption & 5.5 & $4.58-6.42$ & 6.7 & $6.11-7.22$ & 13.5 & $13-13.9$ & 20 & $16-24$ & 0.015 \\
\hline
\end{tabular}

Table 4 Simultaneity of cardiovascular risk factors according to sex, in elderly individuals of El Jadida city

\begin{tabular}{|c|c|c|c|c|c|c|}
\hline \multirow{2}{*}{ Number of risk factors } & \multicolumn{2}{|c|}{ Total $(\mathbf{N}=537)$} & \multicolumn{2}{|c|}{ Male $(\mathrm{N}=401)$} & \multicolumn{2}{|c|}{ Female $(N=136)$} \\
\hline & $\%$ & $95 \% \mathrm{Cl}$ & $\%$ & $95 \% \mathrm{Cl}$ & $\%$ & $95 \% \mathrm{Cl}$ \\
\hline None & $\mathrm{II}, 4$ & II.I7-II.54 & 9 & $8.72-9.22$ & 18,4 & $17.64-19.11$ \\
\hline I & 34,3 & $34.07-34.45$ & 38,9 & $38.56-39.15$ & 20,6 & $19.85-21.32$ \\
\hline 2 & 27,7 & $27.56-27.93$ & 27,9 & $27.68-28.17$ & 27,2 & $26.47-27.94$ \\
\hline 3 & 18,1 & $|7.87-| 8.24$ & 16 & $|5.7|-\mid 6.20$ & 24,3 & $23.52-25$ \\
\hline 4 & 7,1 & $6.8-7.26$ & 6,7 & $6.48-6.98$ & 8,1 & $7.35-8.82$ \\
\hline$\geq 5$ & I,5 & $1.3-1.67$ & I,5 & I.24-I.74 & I,5 & $0.73-2.2$ \\
\hline
\end{tabular}

\section{Discussion}

Identification of risk factors for atherosclerosis is essential for the adoption of preventive measures. This study is carried out on 537 elderly populations of both sexes, in order to determine the prevalence of hypertension, dyslipidemia, diabetes mellitus, tobacco smoking, and obesity, considered risk factors of cardinal importance that can be controlled or even removed.

Systemic arterial hypertension is considered one of the most important causes of morbidity and mortality in adult population worldwide, both by its high prevalence and by its complications. The same level of blood pressure and the risk of atherosclerotic complications are reported in the literature with greater prevalence among men. ${ }^{12}$ The present study data show that systemic arterial hypertension is the most prevalent among the risk factors analyzed (66.1\%), affecting $75.6 \%$ of men and $38.2 \%$ of women, and the difference in prevalence between the two sexes was statistically significant.

This prevalence is much higher than that observed in urban areas of the elderly in the national survey conducted in $2000(52 \%)^{2}$ and 2006 $(33 \%),{ }^{13}$ similar to those observed in Algeria $(67 \%),{ }^{14}$ Togo $(63,8 \%)^{15}$ and France $(67,3 \%)^{16}$ and lower than that reported in Tunisian subjects aged 65 to 69 years $(78 \%)^{17}$ using the same diagnostic criteria, observed in elderly patients systemic arterial hypertension. According to the age group; the prevalence of hypertension significantly increases from $51 \%$ in the $60-64$ age group to $68.9 \%$ in the $65-69$ age group and $70.9 \%$ for $70-74$. This prevalence variation is found also in other studies in Morocco, Tunisia, Algeria, Spain and France ${ }^{16-19}$ and confirmed by The results of the Framingham study.

The epidemic of obesity is a serious world health problem. In our study we found a prevalence of $24.2 \%$, which is similar to that in Algeria (20\%)) but much higher than that recorded in Tunisia (12.6\% of patients aged 65 to 69 years) $)^{17}$ and in France (17\% in subjects aged 70 to 80 years) ${ }^{16}$ However, it is much lower than that recorded in the United States and in Australia. ${ }^{20-22}$ The same observation can be made for abdominal obesity with a predominance in women. This is due to dietary changes, and a marked decrease in physical activity. The increasing prevalence of obesity and global aging of the population implies that the incidence and prevalence of diabetes will continue to rise. Diabetes predicts cardiovascular artery and complications of myocardial infarction in the elderly. ${ }^{23}$

The prevalence of diabetes was $14.9 \%$ among the subjects studied, these results being lower than those observed in other developing countries such as Tunisia (30\%), ${ }^{19}$ Mexico $^{24}$ and Brazil ${ }^{25}$ and, similar to those in France (14\%), ${ }^{26}$ and even greater than that reported in Great Britain (10.3\%) ${ }^{27}$ Our data show that the prevalence of diabetes is similar in women and in men and this is consistent with the results reported by studies in Tunisia, Algeria, and France. ${ }^{16,19,28}$ The plasma lipids as risk factors for atherosclerotic disease have been extensively studied in young and middle aged adults. However, few investigations have been conducted in the elderly. ${ }^{29,30}$ One particular aspect in our population was the weak prevalence of hypercholesterolemia (4\%), 
differently from the present study, a higher prevalence and a decrease of the prevalence with age were reported. ${ }^{31,32}$ The decline of total cholesterol during the past decades has been observed in many developed countries' populations, ${ }^{33}$ this decline could be explained in part by changes in dietary habits particularly linked to a decrease in trans fatty acids, saturated fatty acids and cholesterol intake. ${ }^{34}$ The importance of triglycerides as a risk factor for atherosclerosis, both in elderly and middle- aged individuals, and its complications have been debated in the literature ${ }^{35}$ with a good controversy. It has been demonstrated by comparing normal individuals, both young and aged, that triglycerides rise significantly during the aging process in both sexes. ${ }^{36}$ In our study, $12.3 \%$ of the studied population showed higher triglycerides levels $(>1.725 \mathrm{mmol} / \mathrm{l})$ with no significant difference between men and women.

Another risk factor for atherosclerotic vascular disease of importance in the elderly is HDL-cholesterol for which analysis has been done in several studies. ${ }^{37}$ According to La Rosa, ${ }^{38}$ the HDLcholesterol levels, usually higher in women, could be one of the reasons why they have a lesser risk of atherosclerotic complications than men. In our study, we observed that HDL-cholesterol $<0.9 \mathrm{mmol} / 1$ corresponded to a greater prevalence of atherosclerotic complications in women $(22.8 \%)$ as compared with men $(14 \%)$.

The role of tobacco in the genesis of vascular accidents of arterial origin is very important. According to WHO, tobacco accounts for $20-25 \%$ of cardiovascular deaths, corresponding to 5.8 million deaths per year. ${ }^{39}$ The proportion of smokers in the studied population was $6.7 \%$, weaker than that observed in Tunisia $(30 \%),{ }^{17}$ in Algeria $(17 \%),{ }^{28}$ in France $(10 \% \text { in subjects aged } 60 \text {-70years })^{16}$ and in the Brazilian population (12.7\%). ${ }^{31}$ The comparison shows that Tunisian women are much more influenced by the Western way of life than the Moroccan and Algerian women. No difference was observed between the elderly individuals aged between 60 and 64years when compared to the older age group category in the present study. In general, the prevalence of smoking among the elderly is lower than that observed among the younger individuals. This could be explained by an interruption of the habit of smoking with the aging process, the presence of morbidities, the differences between generations or the premature death of smokers. However, elderly smokers, present a higher risk of developing diseases related to smoking when compared to younger smokers as they tend to present a longer and more intense exposure to tobacco. ${ }^{40}$

Elderly individuals with two or more simultaneous cardiovascular risk factors were $54.3 \%$, whereas, this simultaneity was superior in another study carried out on individuals aged 60 or older. ${ }^{31}$ The cardiovascular risk factors tend to occur simultaneously and their combination generally represents an increased total risk resulting from the sum of their isolated effects, which might indicate a synergic effect among factors. ${ }^{41-43}$

\section{Conclusion}

The present study characterizes for the first time cardiovascular diseases risk factors in Moroccan elderly population. The study demonstrated a high prevalence of cardiovascular diseases among Moroccan elderly Individuals in the city of El Jadida, The cardiovascular risk factors occur simultaneously in more than half of this population age category, and the most prevalent ones were: arterial hypertension, central obesity and total obesity particularly in women. It is essential that those concerned with public health be aware of the increased prevalence of this problem in Morocco.
Studies in aging adult populations must consider the bias produced by an increased early mortality in those with a more unfavourable profile. There is an urgent need to improve attitudes toward screening, preventing, and treatment of coronary risk factors in older people. Primary intervention should be the goal; obesity, once established is often intractable.

\section{Acknowledgements}

None.

\section{Conflict of interest}

The author declares no conflict of interest.

\section{References}

1. Rekia Belahsen, Odilia I Bermudez, Mziwira Mohamed, et al. Obesity and related metabolic disorders are prevalent in Moroccan women of childbearing age. Int J Diabetes \& Metabolism. 2005;13:159-166.

2. Tazi MA, Abir Khalil S, Chaouki N, et al. Prevalence of the main cardiovascular risk factors in Morocco: results of a National Survey 2000. J Hypertens. 2003;21(5):897-903.

3. Haut Commissariat au Plan. Rapport sur Les personnes âgées au Maroc. 2006.

4. Envoyer à un ami. Présentation des principaux résultats du RGPH. 2014.

5. Recensement Général de la Population et de l〉habitation. Caractéristiques démographiques et socio-économiques: Régionale de Doukala-Abda. Maroccco: Haut Commissariat au Plan, Direction Régionale de DoukalaAbda; 2004.

6. World Health Organization. Obesity: preventing and managing the global epidemic. Report of a WHO consultation. World Health Organ Tech Rep Ser. 2000;894:1-253.

7. Olinto MTA, Nacul LC, Gigante DP, et al. Waist circumference as a determinant of hypertension and diabetes in Brazilian women: a population-based study. Public Health Nutrition. 2003;7(5):629-635.

8. WHO. Obésité: prévention et prise en charge de l'épidémie mondiale. Rapport d'une consultation de l'OMS. Switzarland: OMS, Série de Rapports techniques 894; 2003. 284 p.

9. Expert Panel on Detection, Evaluation, and Treatment of High Blood Cholesterol in Adults. Executive summary of the third report of the National Cholesterol Education Program (NCEP) expert panel on detection, evaluation, and treatment of high blood cholesterol in adults (Adult Treatment Panel III). JAMA. 2001;285(19):2486-2497.

10. Friedewald WT, Levy RI, Fredrickson DS. Estimation of the concentration of low-density lipoprotein cholesterol in plasma, without use of the preparative ultracentrifuge. Clin Chem. 1972;18(6):499-502.

11. ANAES (Agence Nationale d'Accréditation et d'Evaluation en Santé). Modalite's de de'pistage et diagnostic biologique des dyslipidémies en prévention primaire. Journal des Maladies Vasculaires. 2000;27(4):226230.

12. Hall PM. Hypertension in women. Cardiology. 1990;77(suppl 2):25-30.

13. Recensement Général de la Population et de l'habitation. Enquête nationale sur les personnes âgées au Maroc 2006. Marocco: Haut Commissariat au Plan; 2006.

14. Jaques D. Vieillissement dans le monde. Paris: CNRS; 2006. 53 p.

15. Damorou F, Pessinaba S, Tcherou T. Hypertension artérielle du sujet noir âgé de 50 ans et plus à Lomé :aspects épidémiologiques et évaluation du risque cardiovasculaire. Annales de cardiologie et d'angéologie. 2010. 
16. Hélène GT, Michel V, Amivi N, et al. Niveau tensionnel moyen et prévalence de l'hypertension artérielle chez les adultes de 18 à 74 ans, ENNS 2006-2007. BEH thématique, 2008:49-50.

17. Elasmi M, Feki M, Sanhaji H, et al. Prévalence des facteurs de risque cardiovasculaires conventionnels dans la population du Grand Tunis. Rev Epidémiol Sante Publique. 2009;57:87-92.

18. Dórea EL, Lotufo PA. Framingham Heart Study e a teoria do contínuo de Pickering:duas contribuições da epidemiologia para a associação entre pressão arterial e doença cardiovascular. Rev Bras Hipertens. 2001;8(2):195-200.

19. Mohamed Mziwira, Mohammed El Ayachi, Denis Lairon, et al. High blood pressure in urban Moroccan women from an agricultural region. Mediterr J Nutr Metab. 2011;4:111-116.

20. Houston D, Nicklas B, Zizza C. Weighty concerns: The growing prevalence of obesity among older adults. $J$ Am Diet Assoc. 2009;109(11):1886-1895.

21. Fakhouri THI, Ogden CL, Carroll MD, et al. Prevalence of Obesity among Older Adults in the United States, 2007-2010. USA: Centers for Disease Control and Prevention, US Department of Health and Human Services; 2012.

22. Mitchell RJ, Lord SR, Harvey LA, et al. Associations between obesity and overweight and fall risk, health status and quality of life in older people. Aust N Z J Public Health. 2014;38(1):13-18.

23. Simons LA, Friedlander Y, Mc Callum J, et al. The Dubbo Study of the health of elderly: correlates of coronary heart disease at study entry. JAGS. 1991;39(6):584-590.

24. Lerman GI, Villa A, Llaca MC, et al. The prevalence of diabetes and associated coronary risk factors in urban and rural older Mexican populations. J Am Geriatr Soc. 1998;46(11):1387-1395.

25. Fagot-CampagnaA1, Bourdel-Marchasson I, SimonD. Burden of diabetes in an aging population: prevalence, incidence, mortality, characteristics and quality of care. Diabetes Metab. 2005;31(2):535S-552S.

26. Husten L. Global epidemic of cardiovascular disease predicted. Lancet. 1998;352(9139):1530.

27. Yahiz-Berrouiguet A, Benyoussef M, Megunni K. Enquêté sur la prévalence des facteurs de risque des maladies cardiovasculaires à Tlemcen (Algérie). Médecine des maladies métaboliques. 2009;3:313319.

28. Zaoui S, Biémont C, Meguenni K. Approche épidémiologique du diabète en milieu urbain et rural dans la région de Tlemcen (Ouest algérien). Santé. 2007;17(1):15-21.

29. Fletcher AE, Bulpitt CJ. Epidemiological aspects of cardiovascular disease in the elderly. J Hypertens Suppl. 1992;10(2):S51-S58.
30. Pereira JC, Barreto SM, Passos VMA. O perfil de saúde cardiovascular dos idosos brasileiros precisa melhorar: estudo de base populacional. Arq Bras Cardiol. 2008;91(1):1-10.

31. Conceição Ferreira CC, Peixoto Mdo R, Barbosa MA, et al. Prevalence of cardiovascular risk factors in elderly individuals treated in the Brazilian Public Health System in Goiânia. Arq Bras Cardiol. 2010;95(5):621628.

32. Kuulasmaa K, Tunstall Pedoe H, Dobson A. Estimation of contribution of changes in classic risk factors to trends in coronary-event rates across the WHO MONICA Project populations. Lancet. 2000;355(9205):675-687.

33. Houterman S, Verschuren WMM, Oomen CM, et al. Trends in total and high densitylipoprotein cholesterol and their determinants in the Netherlands between 1993 and 1997. Int J Epidemiol. 2001;30(5):10631070 .

34. Leaf DA. Lipid disorders: Applying new guidelines to your older patients. Geriatrics. 1994;49(5):35-41.

35. Figueira Jose L, Papaléo Netto M, Carvalho Filho, et al. Perfil lipídico em indivíduos idosos normais / Lipid profile in normal elderly subjects. Arq Bras Cardiol. 1987;48(2):77-81.

36. Corti MC, Guralnik JM, Salive ME, et al. HDL cholesterol predicts coronary heart disease mortality in older persons. JAMA. 1995;274(7):539-544.

37. La Rosa JC. Dyslipoproteinemia in women and elderly. Med Clin North Am. 1994;78(1):163-180.

38. Benowitz NL, Gourlay SG. Cardiovascular toxicity of nicotine: Implications for nicotine replacement therapy. $J$ Am Coll Cardiol. 1997;29(7):1422-1431.

39. OMS report. Sifting the evidence: gender and tobacco control. Switzerland: World Health Organisation; 2007.

40. Ebrahim S, Montaner D, Lawlor DA. Clustering of risk factors and social class in childhood and adulthood in British women's heart and adulthood in British women's heart and health study: cross sectional analysis. BMJ. 2004;328(7444):861.

41. Ebrahim S, Montaner D, Lawlor DA. Clustering of risk factors and social class in childhood and adulthood in British women's heart and adulthood in British women's heart and health study: cross sectional analysis. $B M J$. 2004;328(7444):861.

42. Qiu Y, Shan B, Yang L, et al. Adipose tissue macrophage in immune regulation of metabolism. Sci China Life Sci. 2016;59(12):1232-1240.

43. Nishimura S, Manabe I, Nagai R. Adipose tissue inflammation in obesity and metabolic syndrome. Discov Med. 2009;8(41):55-60. 